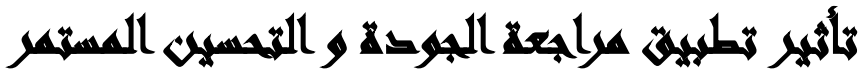

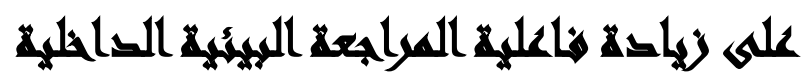

[19]

() كلية التجارة جامعة عبن شبد عبد الحميد(')- جمال سعد خطاب(1)- أماني البري (')

\section{المستخليس}

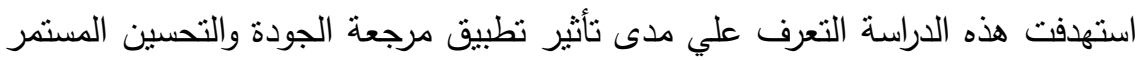

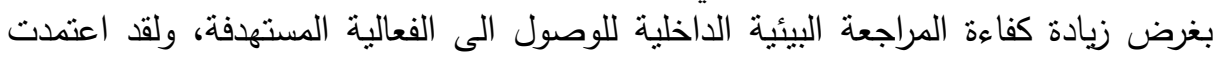

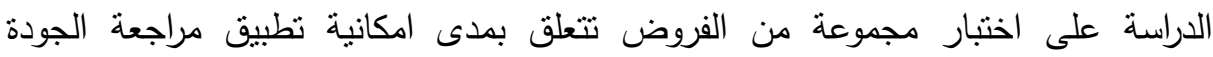

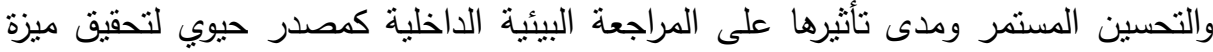

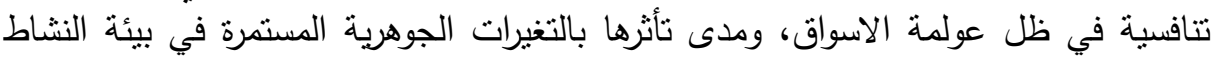

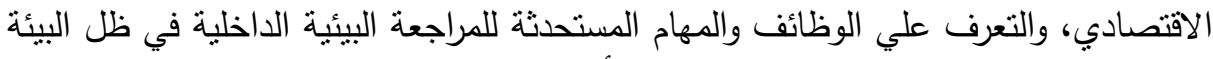
المعاصرة للجودة والتحسين المستمر ، ومدى نأثثير تطبيق مراجعة الجودة والتحسين المستمر في تطويرها و زيادة كفاءتها وفاعليتها.

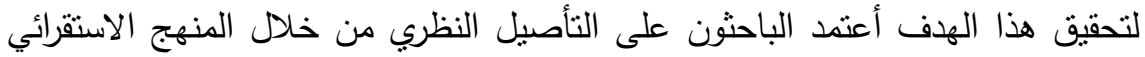

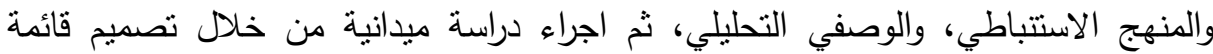

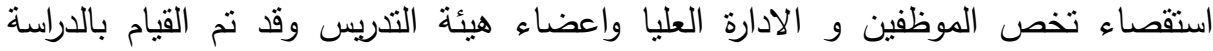

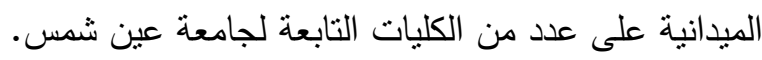

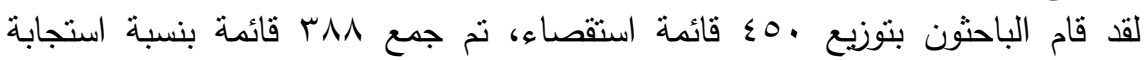

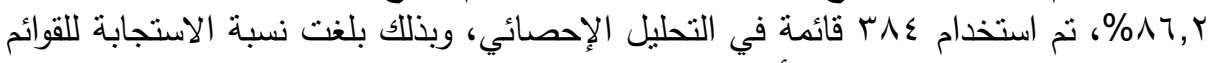

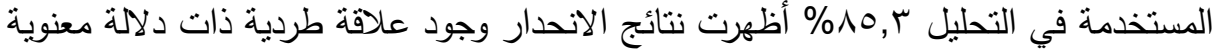

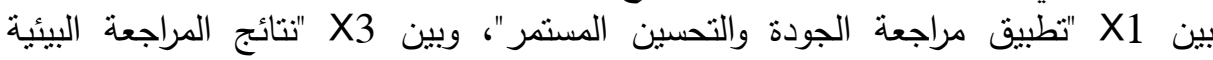

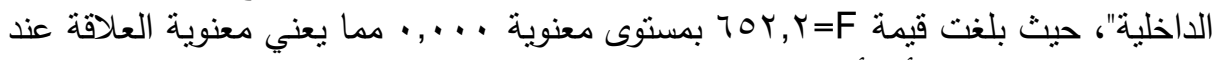

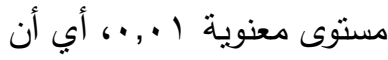
تطبيق مراجعة الجودة والتحسين المستمر يؤثر طردياً على نتائج المراجعة البيئية

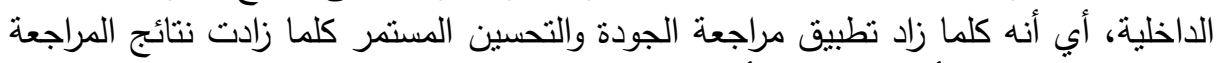

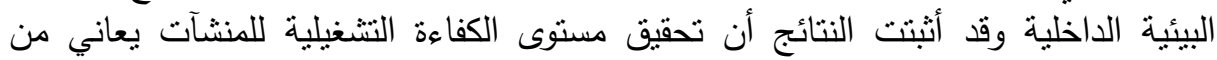

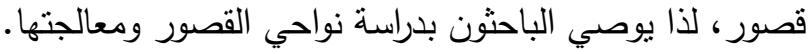
الكلمات الافتتاحية: مراجعة الجودة والتحسين الدستمر - المراجعة البيئية الداخلية

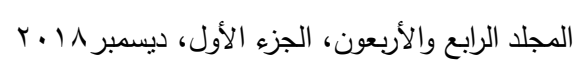




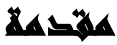

تأثرت مهنة المحاسبة والمراجعة بظروف البيئة التي تعمل فيها ويقاس تقدم هذه المهنة بمدي مواكبتها للتغيرات والتطورات ألبيئية وقد تزايد في السنوات الأخيرة الإدراك العالمي بأهمية المشاكل البيئية في ضوء تحديات التتمية الاقتصادية والاجتماعية القائمة ،كما تزايدت قوانين

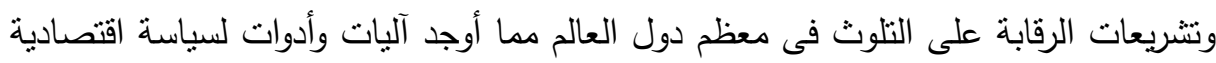
لا تقوم بذلك ا ـ (مشيل نوداور التتمية الاقتصادية).

لقد كان لهذا النطور الذى لحق بالمراجعة البيئية الداخلية فيما يختص بالمراجعة البيئية

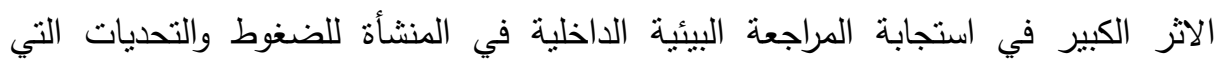
تعترضها من قبل البيئة المحيطة بها والجماعات البيئية المسئولة عن حماية البيئة ،وبذلك استطاعت المراجعة البيئية الداخلية ان تفي بمسؤوليتها ،وتؤدى وظيفتها تجاه البيئة، واظهرت شكلا أخر لسلوك المنشأ ت و صاحب ذلك تغير في النظرة النقليدية للمشروعات وطريقة تقييم

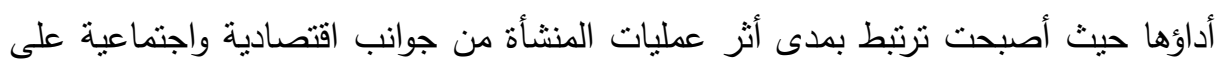
المنشآت الأخرى والمجتمع المحيط، يمكن القول أن المراجعة البيئية عملية منظمة يقتضي أن أن

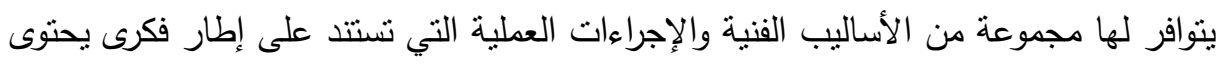

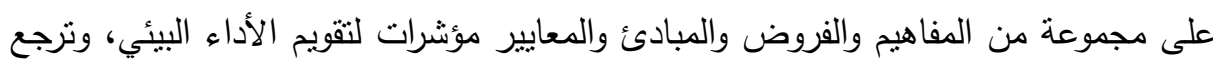

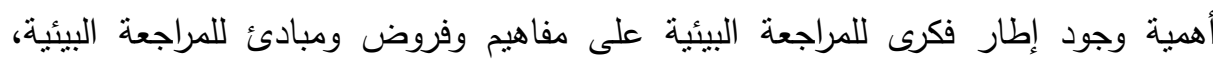

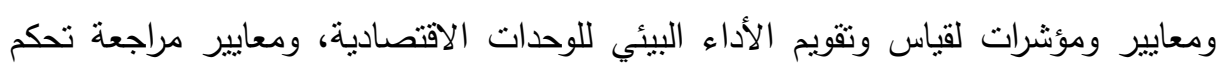
الأداء المهني لعمل مراقب الحسابات عند قيامة بالمراجعة البيئية.

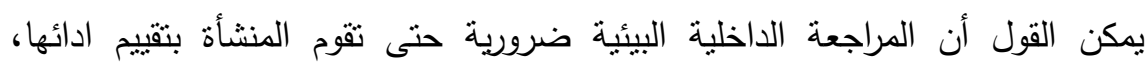
وبالتالي تستطيع ان تقرر فيما اذا كانت تؤدي اهدافها البيئية القانونية والداخلية بالمراجعة اندية

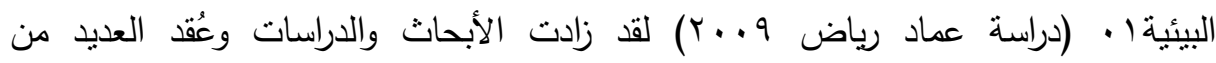
المؤتمرات التي تتصح بنتني المراجعة البيئية كمطلب أساسي لاستجابة المنظمات للبيئة فقد

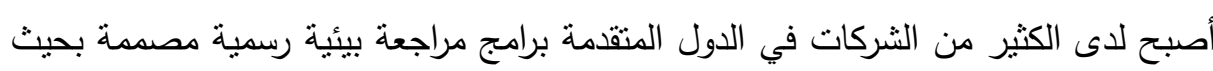
تقدم لهذه الثركات تأكيداً بأنَّ عملياتها ينم إدارتها طبقاً للمعايير والقوانين الحكومية البيئية وطبقاً للسياسات البيئية للوحدة وعلى الرغم من أنَّ المراجعة البيئية قد بدأت كأداة للرقابة لإنة

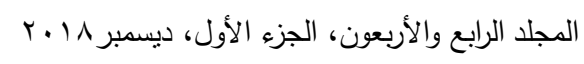


الداخلية فإنَّ الحكومات والرأي العام قد أبدت اهتماماً متزايداً بإناحة نتائج مراجعة البيئة

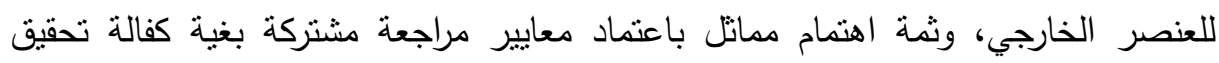

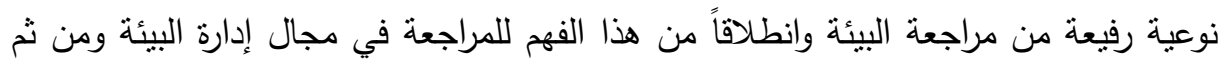

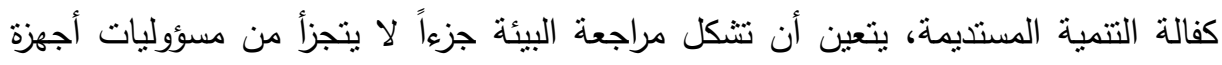

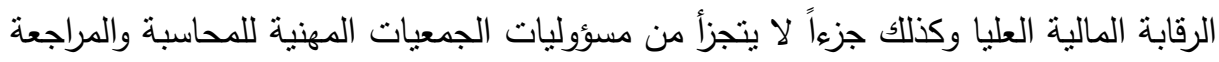

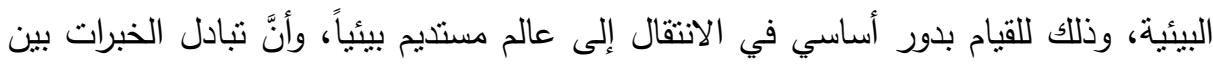

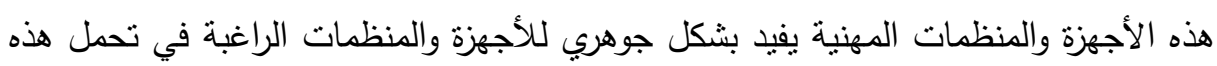

$$
\text { المسؤولية.r دارسة (احمد عبد الرحيم السارع ). }
$$

\section{And}

يمكن ان تتبلور مشكلة البحث في دراسات متعددة مثل (أمين السيد لطفي، هـ . ب)،

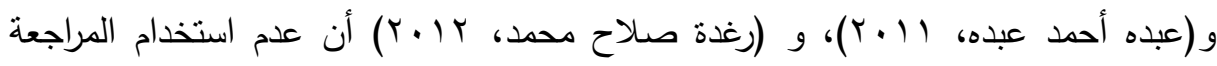

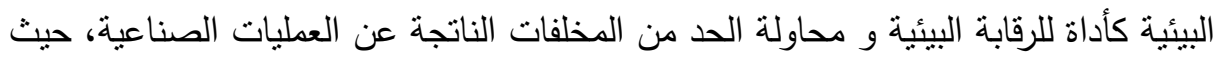

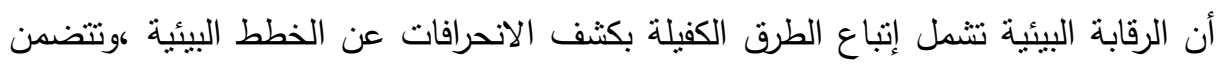

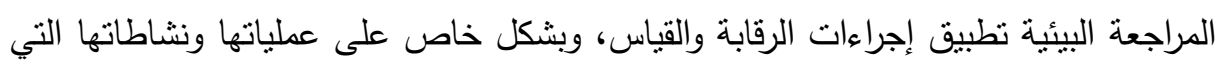

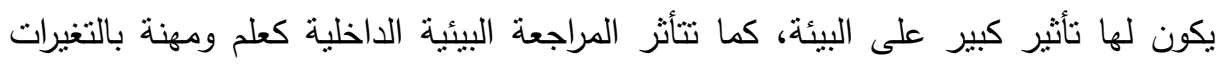

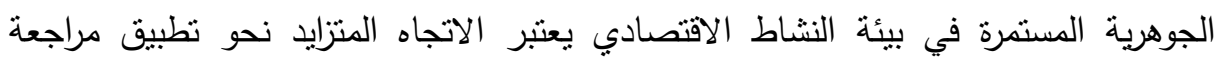

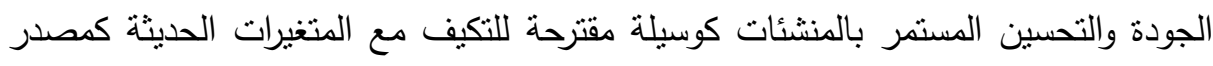
حيوي لتحقيق ميزة تنافسية فى ظل عولمة الأسواق وانشاء مجالا جديدا في مهنة المراجعة بلهن البيئية الداخلية.

ولكى تتجح وظيفة المراجعة البيئية الداخلية في القيام بدورها المهم يجب ان تودي

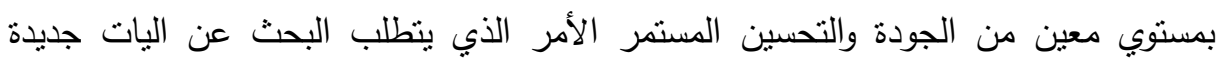

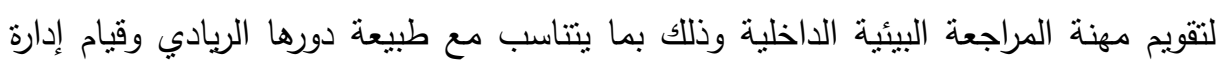
المراجعة بمراجعة الأداء البيئي الذى يؤدى الى تحسين الأداء البيئي للمنشاة.

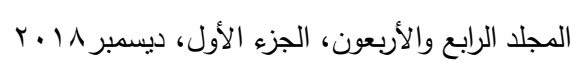


يمكن عرض مشكلة الدارة في سؤال جوهري هو: ما مدى نأثثر نطبيق مراجعة الجودة

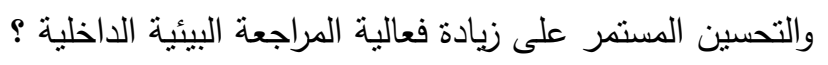

\section{أسريلا المهيش}

ويستمد من السؤال الرئيس عدة اسئلة فرعية وهى:

1- ما مدى تأثثر تطبيق مراجعة الجودة والتحسين المستمر على استقلالية المراجعة البيئية الاخلية؟

r- ما مدي تأثثر تطبيق مراجعة الجودة والتحسين المستمر على نتائج المراجعة البيئية الداخلية؟

r- ما الاجراءات التي يجب اتخذها لتطبيق مراجعة الجودة والتحسين المستمر؟

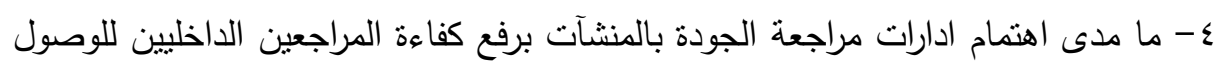

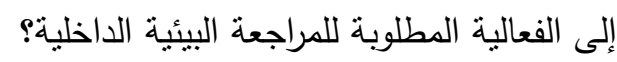

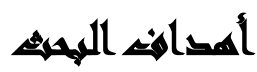

يهاف البحث بثكل رئيسي علي مدى تأثير تطبيق مراجعة الجودة والتحسين المستمر علي زيادة كفاءة المراجعة البيئية الداخلية لتحقيق الفعالية. يمكن تحقيق هذا الهدف من خلال عدة أهداف فرعية وتتمنل في الأهداف التالية: 1- تحديد تأثير مراجعة الجودة والتحسين المستمر وانعكاساتهما على المراجعة البيئية الداخلية. r- توضيح النتائج المترتبة على تطبيق مراجعة الجودة والتحسين المستمر •

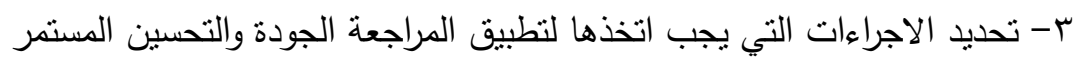
ع - تحديد مدى اهتمام ادارت مراجعة الجودة برفع كفاءة المراجعين الداخليين واثره على فعالية المراجعة البيئية الداخلية. 


\section{أهمهية السراسمة}

بالنسبة للمراجع الداخلي: تعزيز دور المراجع الداخلي في تقييم وتحسين فعالية إدارة المخاطر والأعمال للمنشاة مما يؤدى الى الارتقاء بنشاط المراجعة البيئية الداخلية لمستوى لئي

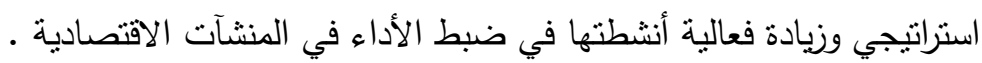
بالنسبة للمراجع الخارجي: تعزيز دور المراجع الداخلي في تقييم وتحسين فعالية إدارة

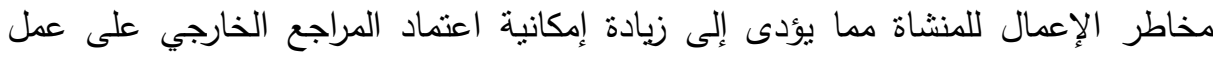

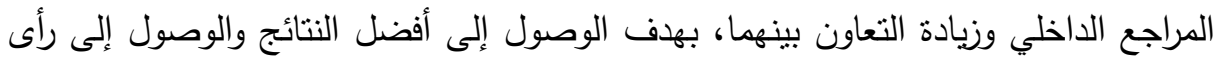
سليم عن مدى تحسين المراجعة البيئية الداخلية في التعبير عن نتيجة النشاط والمركز المالي بالحصول علي أدلة إثبات جديدة نساعده على أداء عملة المهني بالنسبة للمنشاة: يجب إن يتم تعزيز الدور الاستراتيجي للمراجعة البيئية الداخلية في المنشاة بهدف تقييم وتحسين وزيادة فعالية إدارة المخاطر والإعمال للمنشاة سوف يلفت نظر

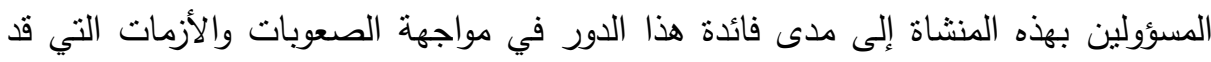

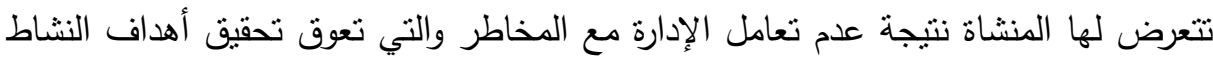
،أو تهدد استمرارية المنشاة في ممارسة نشاطه.

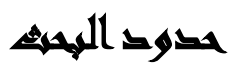

اقتصرت الدراسة علي مجموعة من الكليات التابعة لجامعة عين شمس والبالغ عددهم(9) كليات.

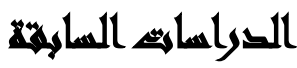

فيما يلي مجموعة من اهم الاراسات السابقة

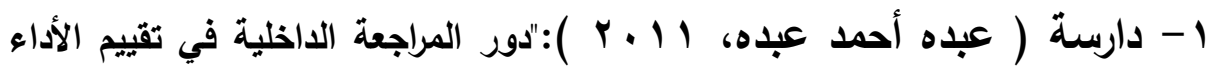
البيئي "دراسة ميدانية ".

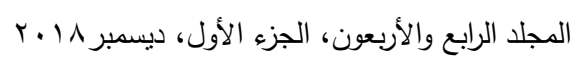


هدفت الدراسة: الى بيان مهام ومسئوليات المراجعين الداخليين عند قيامهم بتقييم الأداء البيئي

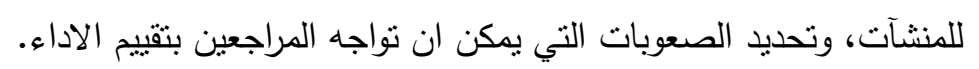

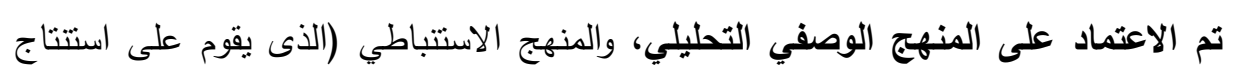

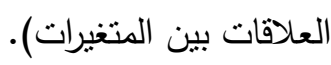
أهم نتائج الدراسة: لا نقوم المنشآت بالوفاء بمسؤوليتها تجاه البيئة المحيطة بها، لا تهنم

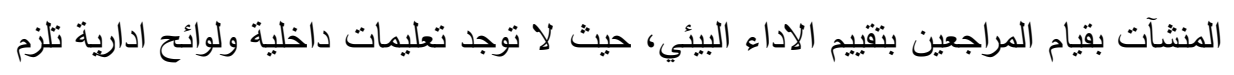
المراجعين بتقييم الاداء البيئي. توصلت الدراسة الى عدة توصيات أهمها: • العمل على نشر الوعى البيئي بين المنشآت والمراجعين الداخليين (عقد ندوات ومؤتمرات) • • العمل على جعل المراجعة الداخلية البيئية مراجعة الزامية. • ايجاد المعايير اللازمة التي تساعد المراجعين الداخليين على القيام بمراجعة الاداء البيئي.

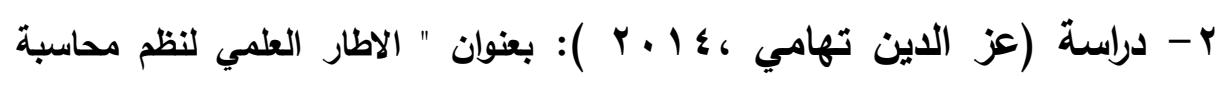
الادارة البيئية " لدالـ هدفت الدراسة: إلي وضع إطار علمي لنظم محاسبة الادارة البيئية يقوم علي أساس تحقيق النرابط بين كل من نظم الادارة البيئية ونظم معلومات المحاسبة الادارية المنطورة. تم الاعتماد على المنهج التحليلي والوصفي.

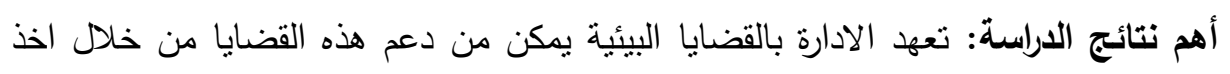
البعد البيئي في الاعتبار من خلال استراتيجية المنشاة. وانتهت الدراسة بتوصيات من أهمها: • ضرورة دمج العوامل البيئية ضمن الوظائف المالية للمنشاة والالتزام بالإفصاح عن ادائها

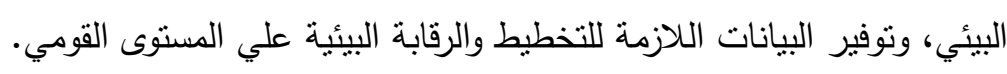

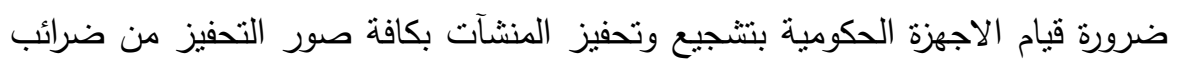

$$
\text { وغيرها علي تطبيق نظام الادارة البيئية . }
$$

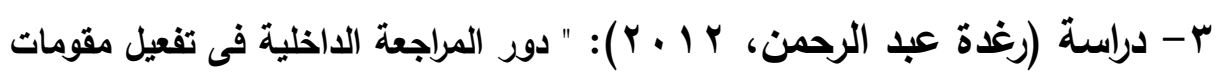

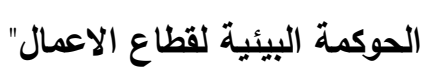


يهاف البحث الى توضيح دور المراجعة البيئية الداخلية في تحسين الاداء البيئي للشركات

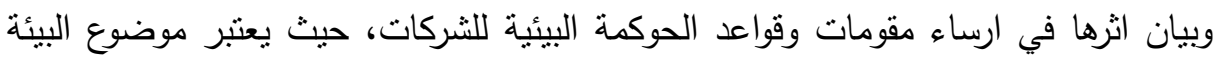
والمحافظة عليها من الموضوعات التي حظيت بدرجة كبيرة من الاهتمام العالمي واصبحت ذات اهمية للمؤسسات والثركات التي تسابقت نحو تطبيق المستحدث في مجال البيئة والتي كان احدثها المواصفات القياسية ايزو ا ل..ء ا، وتأتي المراجعة الداخلية لتحقيق الرقابة في محاولة للمساهمة في الحد من المخلفات الناتجة عن العمليات الصناعية. ع - دراسة (vivi,N 2012) المراجعة البيئية - التحديات الحالية والمستقبلية هدفت الدراسة: إلى معرفة التحديات الحالية والمستقبلية للمرجعة البيئية، الحد من تطور المشاكل البيئية على المدى الطويل، الاتجاه الى العولمة زاد من الثاكل البيئية، معالجة

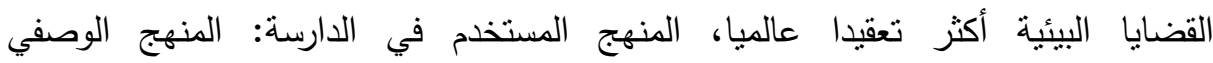
والاستنباطي. الهم نتائج الاراسة المراجعة البيئية هى اصعب انواع المراجعة لصعوبة الحصول على الصى البيانات البيئية، وان قضية البيئة مهمة وحساسة حيث زادت الحاجة الى المراجعة البيئية

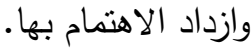
وانتهت الدراسة بتوصيات الهمها: • ضرورة ان تبذل مهنة المحاسبة والمراجعة مجهودا أكبر للوصول بنشاطها الى الامور البيئية • • ضرورة وضع مدخل استراتيجي منظم للمراجعة البيئية.

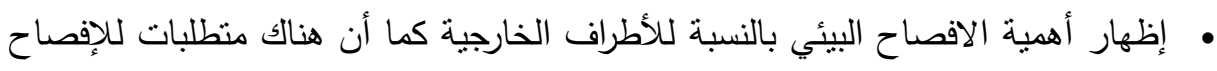
• يجب علي المنشاة مراعاتها، الحفاظ على النزاهة والثفافية. 
ه- دراسة ( M ihaela U , 2013 ): ترى الدارسة أن المراجعة البيئية أسلوب منعدد

التخصصات في البيئة الطبيعية التى تعمل فيها وتهدف الدراسة إلي التعرف على علاقة المراجعة البيئية بعمليات التصنيع وتخزين المواد مع تحديد الاثار والمسئوليات ذات الصلة.

وتتعرض الدراسة للاستخدام غير الرشيد للموارد الطبيعية علي طول الوقت وتزايد المخاوف من هذه المشكلة على اعتبار انها تهدد مصالح الاجيال القادمة.

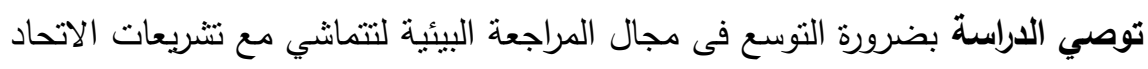
الاوربي حتى تتحقق الفوائد المرجوة منها على المدى المتوسط والطويل.

\section{هتغيوايت التراسما}

1 - المتغير المستقل: ينمثل في نطبيق مراجعة الجودة والتحسين المستمر :

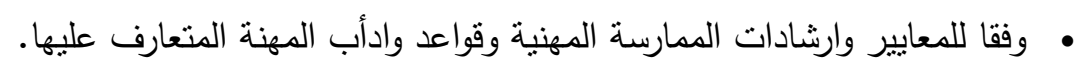
• ودة اداء المراجعة تساعد علي التحسين المستمر في اداء خدمات المراجعة البيئية الداخلية.

r - المتغير التابع: ويتمثل في زيادة فعالية المراجعة البيئية الداخلية: • تحديد أهداف وصلاحيات ومسئوليات المراجعة البيئية الداخلية.

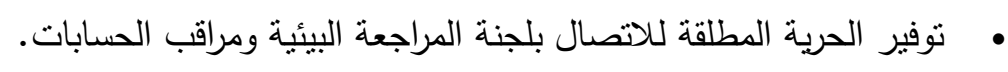
كفاءة المراجعين الداخليين ويمكن قياسها من خلال: • المؤهلات العلمية والخبرة، سياسة التعين بإدارة المراجعة البيئية الداخلية. • الرقابة على جودة المراجعة البيئية الداخلية من خلال التقييم الخارجي لأعمال المراجعة.

\section{هروض اللهمهي}

لا نوجد علاقة جوهرية بين نطبيق مراجعة الجودة التحسين المستمر وبين زيادة فعالية

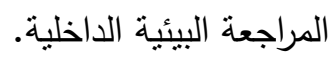


ويشتق من تلك الفرضية الفرضيات الفرعية التالية: • لا توجد علاقة جوهرية بين تطبيق مراجعة الجودة والتحسين المستمر واستقلالية المراجعة البيئية الداخلية. • لا توجد علاقة جوهرية بين تطبيق مرجعة الجودة والتحسين المستمر ونتائج المراجعة البيئية

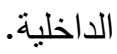
• لا توجد علاقة جوهرية بين اجراءات تطبيق الجودة والتحسين المستمر وفعالية التقارير .

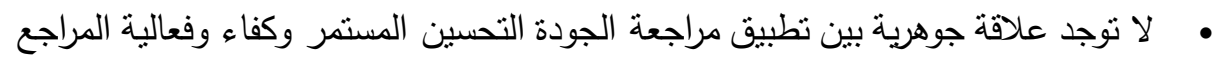
الاخلي.

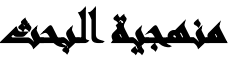

تستمد هذه الدراسة اهميتها من الموضوع ومدى ضروريته في ظل تطبيق مراجعة الجودة

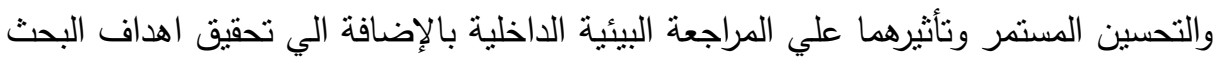
يعتمد الباحث على المنهج الاستقرائي والمنهج الاستتباطي والوصفي التحليلي وذلك على النحو لإنها

الدراسة النظرية: وتتم من خلال دراسة وتحليل الدراسات الأكاديمية للمراجعة عن موضوع البحث، وتتمنل في أهم المصادر التي على المعلومات اللازمة فى الكتب والدوريات الأجنبية والعربية وكذلك ما أصدرته الهيئات والمنظمات المهنية المحاسبية عن موضوع البهات البحث. الدراسة الميدانية: وتتم من خلال إعداد قائمة استبيان لمعرفة أراء عينة من المراجعين الداخليين والموظفين - والادارات العليا - واعضاء هيئة التنريس بالكليات التابعة لجماعة عين شمس.

\section{المخاهيه مصطلحاهي التوراسة}

ا - مراجعة الجودة والتحسين المستمر: تعتبر مراجعة الجودة والتحسين المستمر أحد الاتجاهات الحديثة المطبقة في معظم الثركات ومن أهم مبادئها رضا العميل والتحسين والتطوير المستمر وتقليل التكلفة والعيوب لأقصى حد ممكن واستخدام الطرق والأساليب

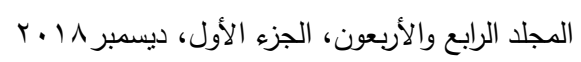


الإحصائية، التدربب المستمر للمرجع الداخلي على مراجعة انشطة الجودة والتحسين

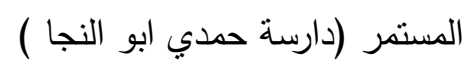

r - المراجعة البيئية الداخلية: الإجراءات التي من شأنها أن تعزز قدرات النظام على الى إنتاج المستويات المحددة للجودة ويتعدى نطاقها إدارة الإنتاج والعمليات إلى كافة الإدارات

$$
\text { الأخرى في الثركة. }
$$

ذللك للتكيف مع التطورات الجوهرية التي تحدث في البيئة المحيطة بها وفي مفاهيم ومداخل العلوم الأخرى وما تحمله من أساليب واتجاهات إدارية متطورة تتطلب من بخدمات مهنية المراجعة

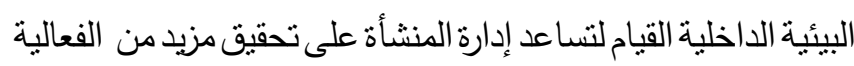
r- الفعالية: هي القدرة على تحقيق الاهداف المخططة للثركة وذلك من خلال تطبيق مراجعة الجودة والتحسين المستمر ، تحديد اهداف وصلاحيات ومسئوليات ادارة المراجعة البيئية ودعم الادارة العليا لإدارة المراجعة البيئية الداخلية، الالتزام بالمعايير المهنية

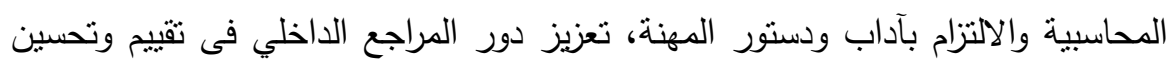
فعالية ادارة المخاطر والاعمال للمنثاة مما يؤدى الي الارتقاء بنشاط المراجعة البيئية

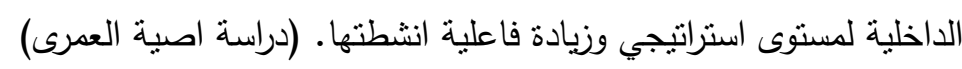

\section{الإطار اللنظليه}

شهدت المراجعة نمواً وتطوراً كبيراً خلال العقدين الماضيين من نهاية القرن العشرين

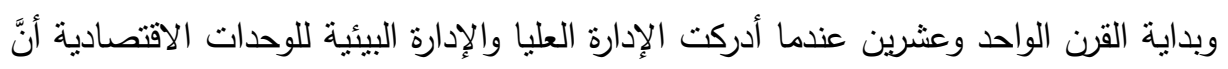

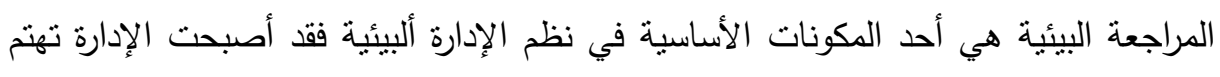

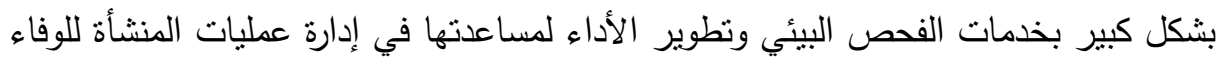

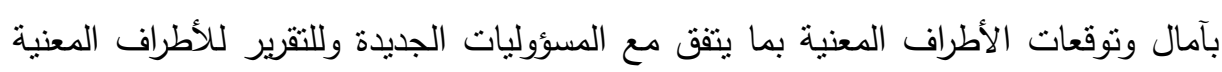
عن كيفية نهوض المنشأة بنلك المسؤوليات وتقع هذه الاختبارات وعمليات الفحص المختلفة لمعنة تحت عنوان " المراجعة البيئية." 
مفهوم المرجعة البيئية: يمكن تعريف المراجعة البيئية بشكل عام بأنها: ا- فحص منظم وموثق ودوري وموضوعي بواسطة الوحدة الاقتصادية أو أي جهة خارجية، التعرف علي مدى انسجام عمليات التشغيل والممارسات المختلفة مع المتطلبات القابلة للنطبيق. ب - فحص انتقادي دوري منظم وموثق وموضوعي بواسطة جهة مستقلة ذات سلطة قانونية للعمليات الانتاجية، وما يرتبط بها من أنشطة فرعية لتحديد نأثيرها على البيئة ومتغيراتها.

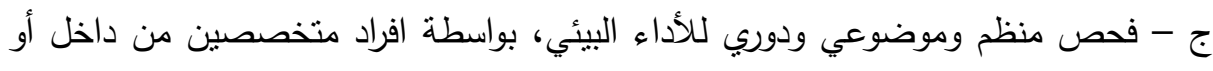
خارج الوحدة الاقتصادية للتأكد من الالتزام بالقوانين والسياسات الادارية وتقيم فعالية

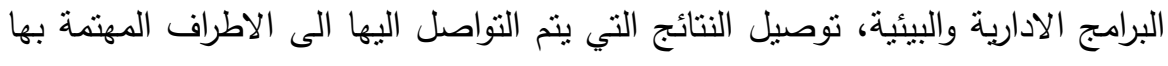
يتضح من التعاريف السابقة انالمراجعة البيئية إما أن تتم داخليا بواسطة المنشاة، وبالتالي يتم الاعتماد على قسم المراجعة في المنشاة لإنجازها، واما ان تتم بواسطة جهة خارجية مستقلة، وذلك عن طريق الاستعانة بالمراجعين الخارجين. بذلك فان المراجعة البيئية قد فل تكون مراجعة داخلية تستخدم نتائجها لأغراض ادارة المنشاة، أو قد تكون مراجعة خارجية تنتخدم نتاجها لأغراض جهات اخرى بخلاف الادارة .

\section{إجبراعاهـ التواسة}

تمهيد: يتعرض هذا الفصل للتحليل الإحصائي لبيانات الدراسة الميدانية بغرض اختبارات الفروض التي تفيد في التعرف على "تأثير تطبيق مراجعة الجودة و التحسين المستمر على لاده زيادة فاعلية المراجعة البيئية الداخلية".

وفى ضوء ذللك يعرض الباحثون أسلوب جمع البيانات، ومراحل إعداد قائمة الاستقصاء

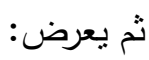
أولاً: أسلوب جعمع البيانات: تتعدد الأساليب المستخدمة في جمع البيانات فمنها الملاحظة، والمقابلات الثخصية، وقوائم الاستقصاء وقد قام الباحثون باستخدام أسلوب قوائم 
الاستقصاء لأنه يعد من أفضل أساليب الدراسات الميدانية، حيث أنه يعتبر أسلوباً ملائما من حيث الوقت والتكلفة، كما يتميز بالوضوح والبساطة، بالإضافة إلى سرية البيانات. ثانياً: إعداد قائمة الاستقصاء: أبعاد ومحاور الاستقصاء:

1 - تحديد دور مراجعة الجودة والتحسين المستمر وانعكاساتهما علي المراجعة البيئية الداخلية. ( $)$

r-فعالية مخرجات قسم المراجعة البيئية الداخلية ( التقارير ). ( وعدد أسئلته \) • ب-توضيح النتائج المترنبة على تطبيق مراجعة الجودة والتحسين المستمر • ( عدد أسئلته ؟).

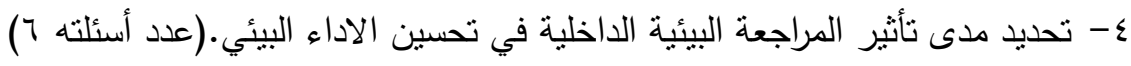
ه-نظوير ورفع كفاءة المراجع الداخلي.( عدد أسئلته7) قام الباحثون بتصميم قائمة استقصاء وعرضها على المختصين لتحكيمها، وبعد إقرارها من قبل المحكمين قام باختبارها، حيث قام بتوزيع قائمة الاستقصاء على عينة اسنطلاعية لمعرفة مدى وضوح الأسئلة وملاحظات المستقصي منهم، وقد استخدم في ذلك أسلوب

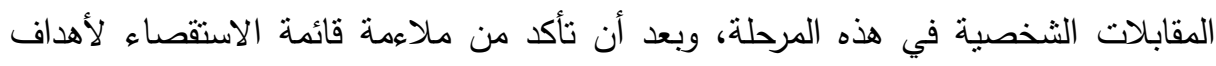

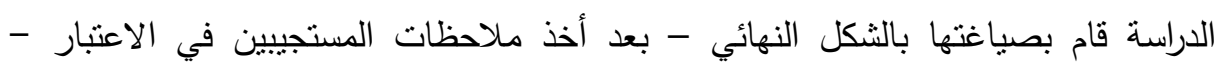
وتوزيعها على عينة البحث. ثالثاً: مجتمع الدراسة: يقتصر مجتمع الدراسة على مديرو الادارات العليا - اعضاء هيئة

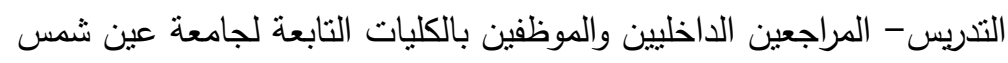
رابعاً: عينة الدراسة: قام الباحث بسحب عينة بلغت عــ فرداً من مجتمع الدراسة، وقد استخدم الباحثون الصيغة التالية في تحديد حجم العينة: $n=\frac{z^{x} p q}{D^{2}}$

حيث: P: (1) نسبة الظاهرة في المجتمع ويمكن اعتبارها . 0\% لأنها تعطي أكبر حجم للعينة. q

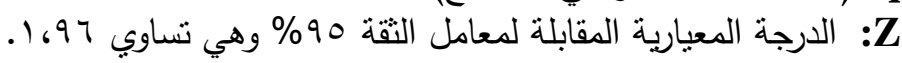




$$
\text { n: Dجم العينة. الخطأ المسموح به، في حدود 0\%. }
$$

وبالتطبيق في الصيغة

$$
n=\frac{1.96^{2}(0.5)(0.5)}{0.05^{2}}=384
$$

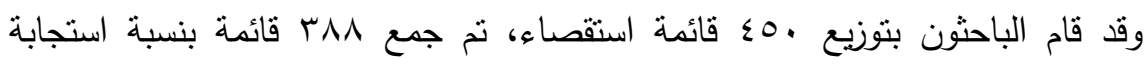

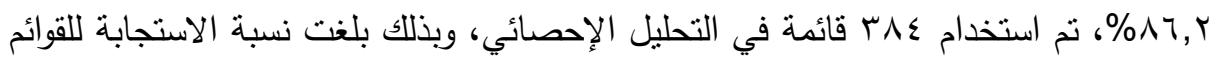

\begin{tabular}{|c|c|c|c|c|}
\hline \multicolumn{2}{|c|}{ القوائم المستخدمة في التحليل } & \multicolumn{2}{|c|}{ القوائم المستوفاة } & \multirow{2}{*}{ القوائم الموزعةً } \\
\hline$\%$ & عدد & $\%$ & عدد & \\
\hline$\Lambda 0, \mu$ & $\Gamma \wedge \varepsilon$ & $\Delta \uparrow, r$ & $r \wedge \lambda$ & $\leqslant 0$. \\
\hline
\end{tabular}
المستخدمة في التحليل r/0,\% كما يتضح من الجدول التالي: جدول( (1): القوائم الموزعة والمستوفاة والمستخدمة في التحليل

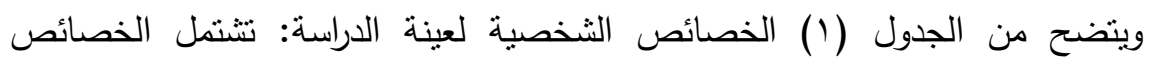

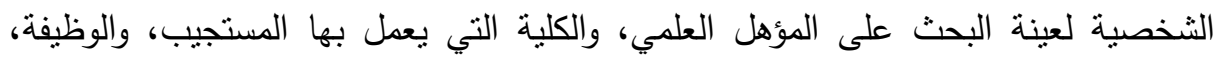

\begin{tabular}{|c|c|c|c|}
\hline نسبة \% & عدد & بيان & الخصائص \\
\hline$r \varepsilon, \cdot$ & 94 & مؤهل متوسط وفوق المتوسط & \multirow{3}{*}{ العلمئهل } \\
\hline$\varepsilon V, 1$ & $1 \wedge 1$ & مؤهل جامعي & \\
\hline$r \wedge, q$ & 111 & مؤهل أعلي من الجامعى & \\
\hline $11, \mathrm{~V}$ & $\varepsilon 0$ & آداب & \multirow{9}{*}{ الكلية } \\
\hline 9,1 & To & البنات & \\
\hline $19, \cdot$ & $\mathrm{VT}$ & تجارة & \\
\hline$\Lambda, \Gamma$ & Tr & آلسن & \\
\hline IT, & 0 . & حقوق & \\
\hline 10,5 & 09 & طب & \\
\hline $7, \wedge$ & rq & طب أسنان & \\
\hline $7, r$ & T乏 & معهد البحوث & \\
\hline $1 \cdot, \varepsilon$ & $\varepsilon \cdot$ & هندسة & \\
\hline $1 \wedge, \wedge$ & VY & وظائف أكاديمية & \multirow{3}{*}{ الوظيفة } \\
\hline$\vee \wedge, 9$ & $r \cdot r$ & وظائف تخصصية & \\
\hline$r, r$ & 9 & وظائف كتابية ومعاونة & \\
\hline $1 \cdots$ & 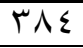 & الإجمالي & \\
\hline
\end{tabular}
وفيما يلي الخصائص الثخصية لعينة الدراسة:

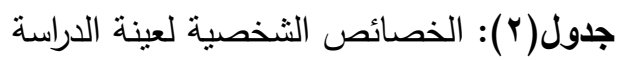


مقياس صدق وثبات المحتوى لمتغيرات الدراسة: تمنل مقاييس صدق وثبات المحتوى لمتغيرات الدراسة: صدق الاستبيان (صدق المحكمين، والاتساق الداخلي)، ومقياس

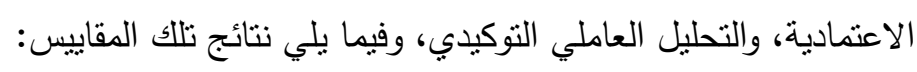

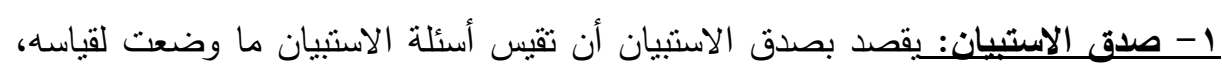
وقام الباحثون بالتأكد من صدق الاسنبيان بطريقتين:

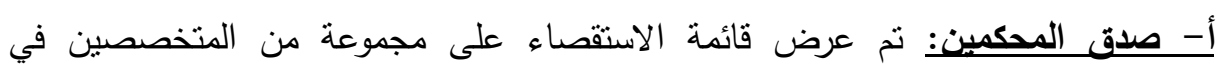

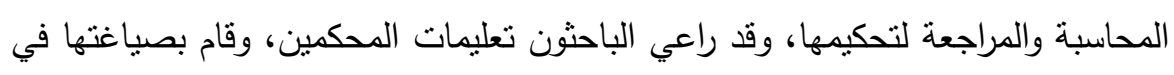

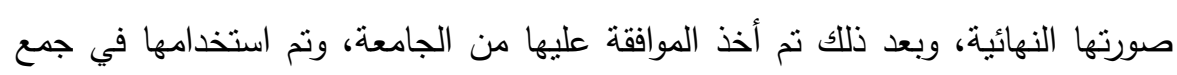
بيانات الدراسة الميدانية. ب- صدق المقياس (الاتساق الداخلي: Internal Consistency): يقصد بالاتساق

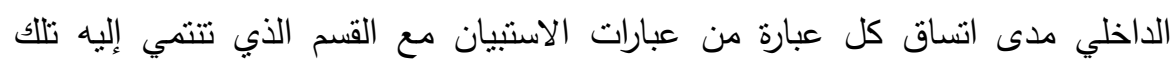

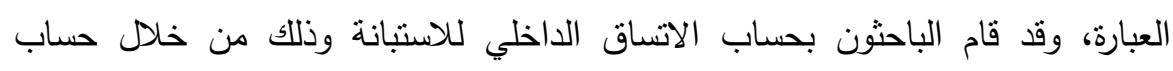

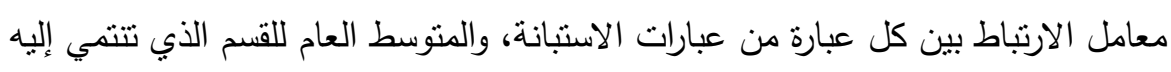

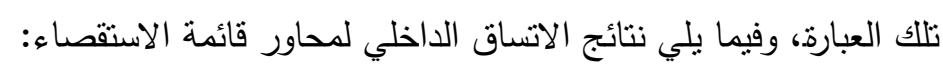
جدول(r): مقاييس الثبات Reliability لمحاور الدارسة

\begin{tabular}{|c|c|c|c|}
\hline الصدق (*) & $\begin{array}{l}\text { معامل } \\
\text { Aif } \\
\end{array}$ & العبارات & المحاور \\
\hline$\cdot, 90$. & $\cdot, q \cdot r$ & $\mathrm{v}$ & الأول: دور مراجعة الجودة والتحسيني المستمر \\
\hline$\cdot, \wedge 01$ & $\cdot, \backslash \backslash \leq \varepsilon$ & $\mathrm{v}$ & الثاني: فعالية مخرجات قالتسم المراجعة البيئية \\
\hline • & $\cdot, \wedge T \vee$ & 7 & الثالث: النتائج المترتبة علي تطبيق مراجعة التمبن \\
\hline$\cdot, 9 \leq$. & $\cdot, \wedge \wedge \mu$ & 7 & الرابع: تحديد مدى تأثير المراج البعة البيئية الداخلية \\
\hline$\cdot, 9 \mu \mathrm{Y}$ & $\cdot, \wedge 79$ & 7 & الخامس: تطوير ورفع كفاءة المراجع الداخلى \\
\hline
\end{tabular}

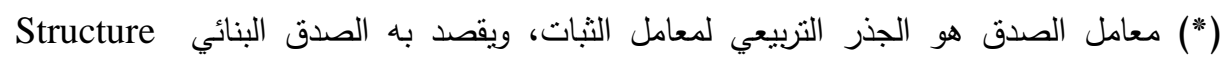
Validity 
يتضح من الجدول(r) السابق أن (معامل الثبات) قيمة ألفا Cronbatch's Alfa قد

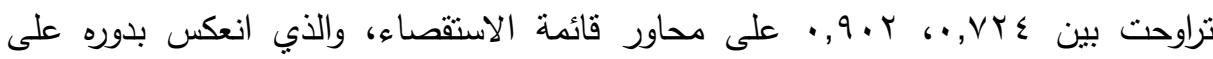

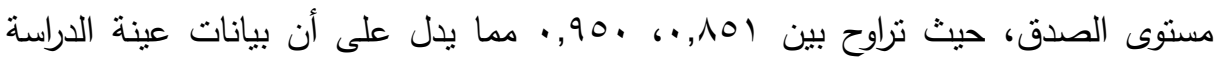

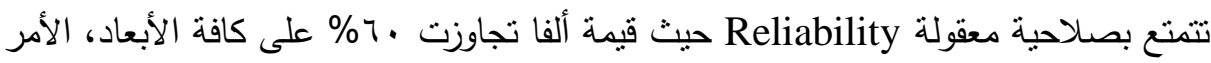

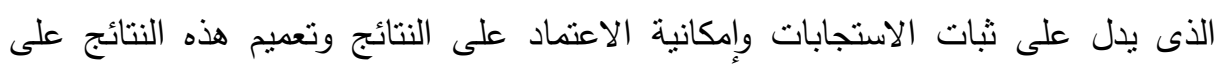
مجتمع الدراسة. جدول(؟): نتائج الانحدار البسيط بين تطبيق مراجعة الجودة والتحسين المستمر ، واستقلالية المراجعة البيئية الداخلية

\begin{tabular}{|c|c|c|c|c|c|c|}
\hline \multicolumn{6}{|c|}{ 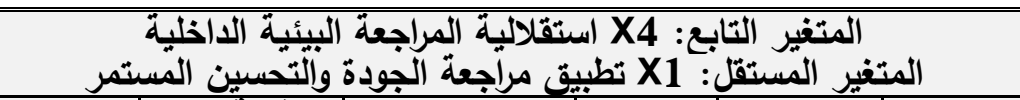 } & \multirow[b]{2}{*}{$\begin{array}{c}\text { F } \\
\text { المحسوية }\end{array}$} \\
\hline المعنوية & 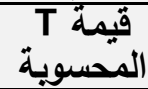 & قيمة المعامل & $\mathbf{R}$ & $\begin{array}{c}R \\
\text { square }\end{array}$ & المعنوية & \\
\hline $\bar{c}, \cdots$ & 7,77 & $\cdot, \wedge \circ \wedge=\alpha$ & \multirow{2}{*}{$\cdot, \vee \leqslant}$. & \multirow{2}{*}{$\cdot, 0 \leqslant 1$} & \multirow{2}{*}{,,$\cdots$} & \multirow{2}{*}{$\varepsilon \pi r, \varepsilon$} \\
\hline$\cdot, \ldots$ & $r_{1,0}$ & $\cdot, \vee 01=\beta$ & & & & \\
\hline
\end{tabular}

يتضح من الجدول (؛) ما يلي: أظهرت نتائج الانحدار وجود علاقة طردية ذات دلالة معنوية بين X1 "تطبيق مراجعة الجودة والتحسين المستمر"، وبين X4 "استقلالية المراجعة البيئية

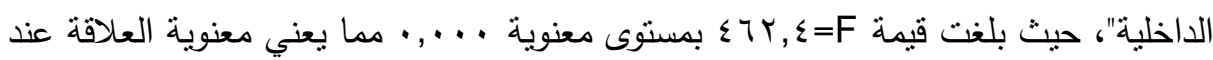

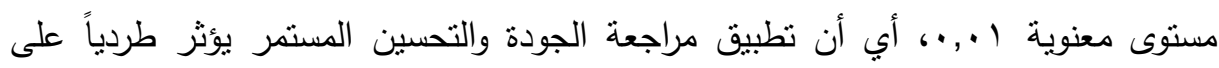

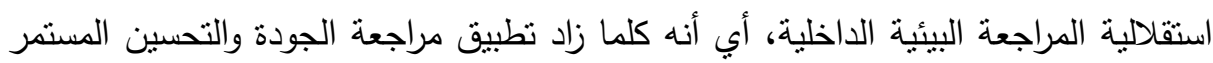
كلما استقلالية المراجعة البيئية الداخلية. - - بعد تقدير معالم نموذج الانحدار يمكن صياغة معادلة الانحدار بالثكل التالي: $\mathrm{X} 4=0.858+0.751 * \mathrm{X} 1+\varepsilon$

X4 استقلالية المراجعة البيئية الداخلية X4 تطبيق مراجعة الجودة والتحسين المستمر X1 ع الخطأ العشوائي 
اختبار معنوية المتغير المستقل: يتضح معنوية المستقل وذلك من اختبار T test حيث بلغت

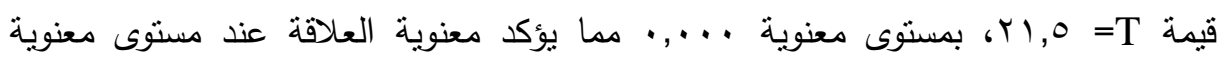

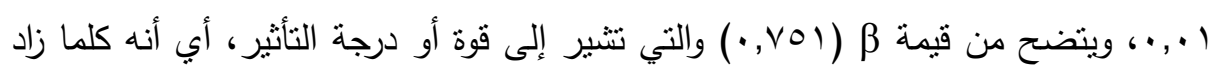

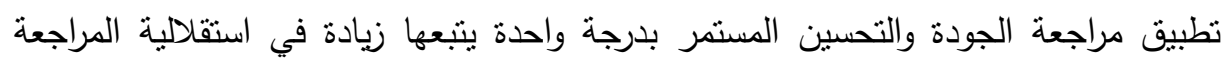
البيئية الداخلية بمقدار ( V01, • • ) درجة.

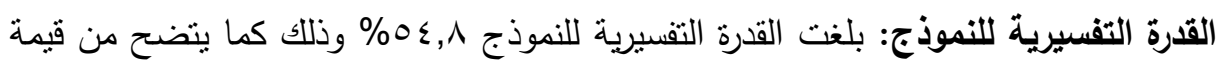
R square

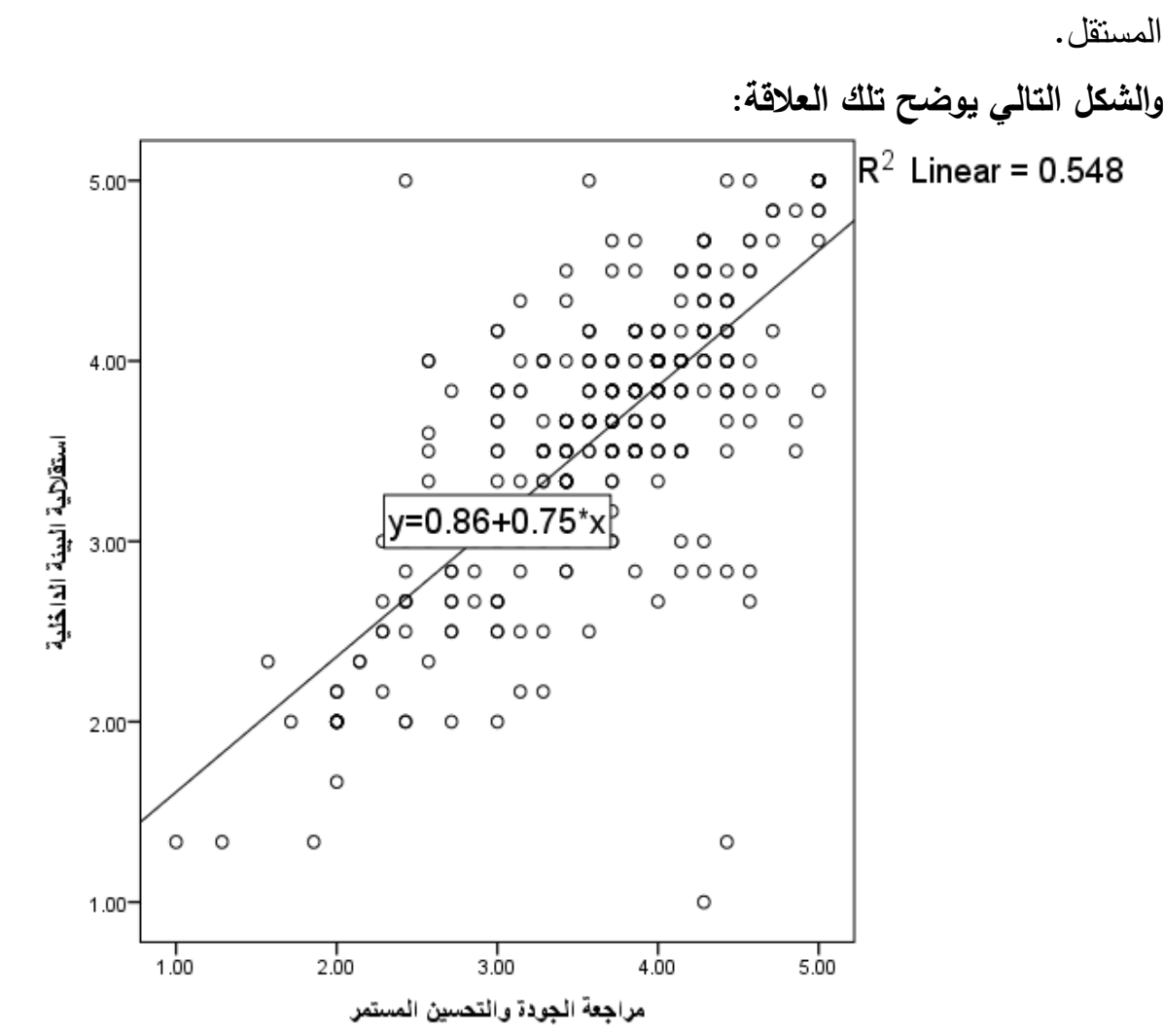

شكل(r): العلاقة بين تطبيق مراجعة الجودة والتحسين المستمر واستقلالية المراجعة البيئية الداخلية 


$$
\text { مما سبق نخلص إلى رفض الفرض الفرعي الأول. }
$$

ب- اختبار الفرض الفرعي الثاني: لا يوجد علاقة ارتباط بين تطبيق مراجعة الجودة

والتحسين المستمر ونتائج المراجعة البيئية الداخلية.

Simple Regression ولاختبار هذا الفرض نم إجراء تحليل الانحدار الخطي البسيط بين نطبيق مراجعة الجودة والتحسين المستمر ، ونتائج المراجعة البيئية الداخلية، وجاءت النتائج كما يلي: جلول(ه): نتائج الانحدار البسيط بين تطبيق مراجعة الجودة والتحسين المستمر، ونتائج المراجعة البيئية الداخلية

\begin{tabular}{|c|c|c|c|c|c|c|c|}
\hline \multicolumn{7}{|c|}{ 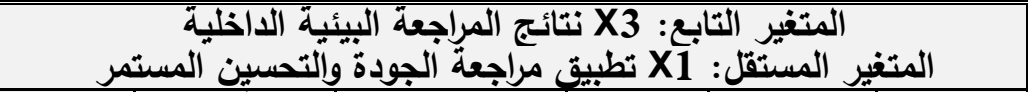 } & \multirow[b]{2}{*}{ F } \\
\hline المعنوية & المحسوية & المعامل & قيم & $\mathbf{R}$ & $\begin{array}{c}R \\
\text { square }\end{array}$ & المنتوية & \\
\hline$\cdot, \cdots$ & $\overline{V, Y Y}$ & 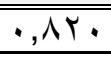 & $=\alpha$ & \multirow{2}{*}{$\cdot, \vee \vee \subseteq$} & \multirow{2}{*}{ ו וT, • } & \multirow{2}{*}{$\cdot, \cdots$} & \multirow{2}{*}{ TOY,Y } \\
\hline$\cdot, \ldots$ & ro, 0 & $\cdot, \vee \wedge \varepsilon$ & $=\beta$ & & & & \\
\hline
\end{tabular}

يتضح من الجدول(0) ما يلي: أظهرت نتائج الانحدار وجود علاقة طردية ذات دلالة معنوية بين X1 "تطبيق مراجعة الجودة والتحسين المستمر"، وبين X3 "نتائج المراجعة البيئية الداخلية"، حيث بلغت قيمة Tor, Y=F بمستوى معنوية . .., . مما يعني معنوية العلاقة عند

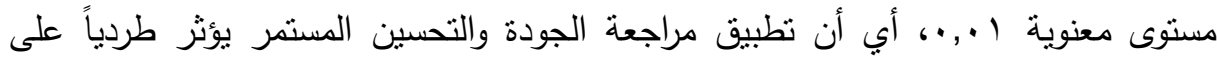
نتائج المراجعة البيئية الداخلية، أي أنه كلما زاد تطبيق مراجعة الجودة والتحسين المسنمر كلما زادت نتائج المراجعة البيئية الداخلية. بعد تقدير معالم نموذج الانحدار يمكن صياغة معادلة الانحدار بالثكل التالي: X3 $=0.820+0.784 * X 1+\varepsilon$ 
اختبار معنوية المتغير المستقل: يتضح معنوية المستقل وذلك من اختبار T test حيث بلغت

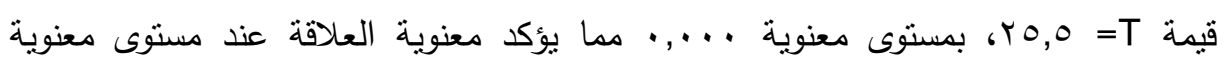

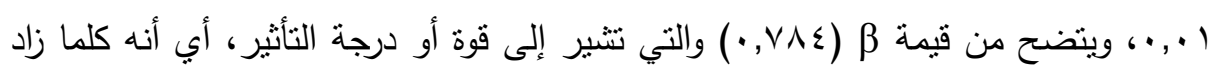
تطبيق مراجعة الجودة والتحسين المستمر بدرجة واحدة ينبعها زيادة في نتائج المراجعة البيئية

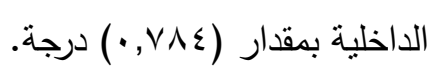

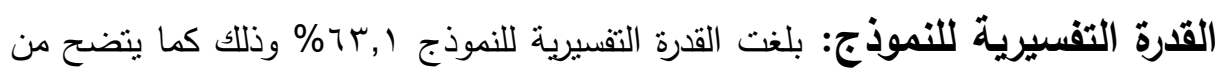
قيمة Rquare أي أن ا,rآ\% من التغيرات التي تحدث في المتغير التابع بشرحها المتغير المستقل. والثكل التالي يوضح تلك العلاقة:

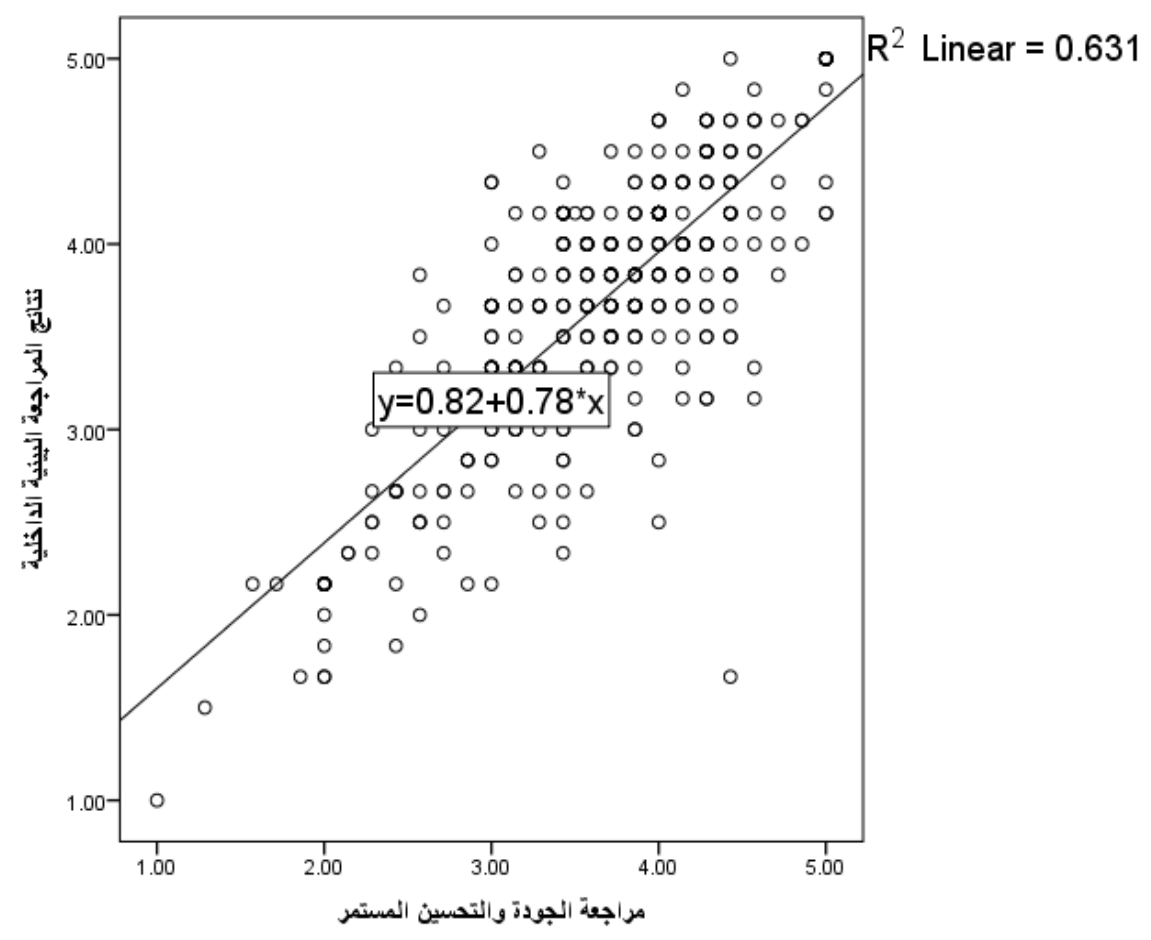

شكل(ץ): العلاقة بين تطبيق مراجعة الجودة والتحسين المستمر ونتائج المراجعة البيئية الداخلية 
مما سبق نخلص إلى رفض الفرض الفرعي الثاني: ج- اختبار الفرض الفرعي الثالث: لا يوجد علاقة ارتباط بين إجراءات تطبيق الجودة التحسين المستمر وفعالية التقارير .

ولاختبار هذا الفرض تم إجراء تحليل الانحدار الخطي البسيط Simple Regression بين تطبيق مراجعة الجودة والتحسين المستمر ، وفعالية القارير ، وجاءت النتائج كما يلي: جدول(†): نتائج الاتحدار البسيط بين تطبيق مراجعة الجودة التحسين المستمر ، وفعالية التقارير .

\begin{tabular}{|c|c|c|c|c|c|c|c|}
\hline \multicolumn{7}{|c|}{ 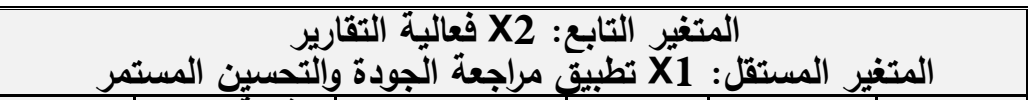 } & \multirow[b]{2}{*}{ المحسوية } \\
\hline المعنوية & 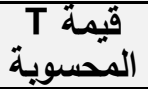 & المعامل & قَ! & $\mathbf{R}$ & $\begin{array}{c}\mathrm{R} \\
\text { square }\end{array}$ & المعنوية & \\
\hline$\cdots$ & $11, r$ & $1, Y 7 V$ & $=\alpha$ & & & & \\
\hline$\cdot, \cdot$ & $\overline{Y Y, \xi}$ & $\cdot, 7 \wedge 0$ & $=\beta$ & $\cdot,, 0$ & & & $0.2,1$ \\
\hline
\end{tabular}

يتضح من الجدول (7) ما يلي: أظهرت نتائج الانحدار وجود علاقة طردية ذات دلالة معنوية

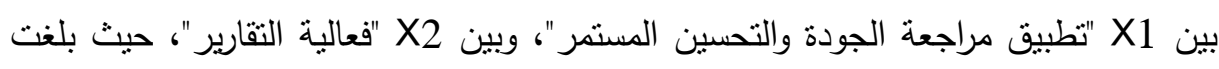

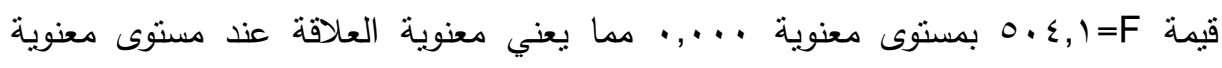

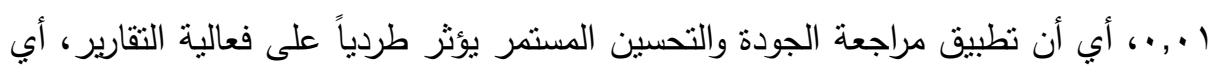

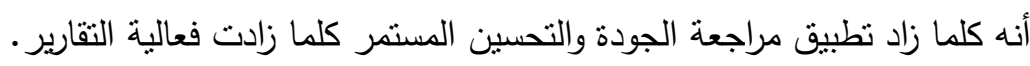
بعد تقدير معالم نموذج الانحدار يمكن صياغة معادلة الاتحدار بالشكل التالي: $\mathrm{X} 2=1.267+0.685 * \mathrm{X} 1+\varepsilon$

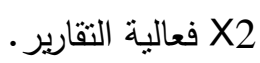
X1 ع الخطأ العشوائي

اختبار معنوية المتغير المستقل: يتضح معنوية المسنقل وذللك من اختبار T test حيث بلغت

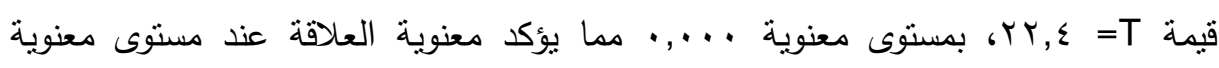

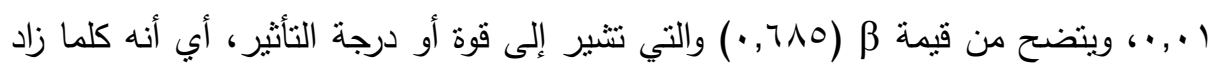

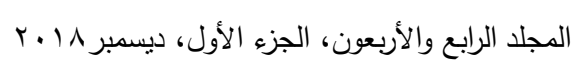


تطبيق مراجعة الجودة التحسين المستمر بدرجة واحدة يتبعها زيادة في فعالية التقارير بمقدار

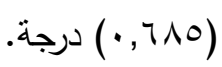

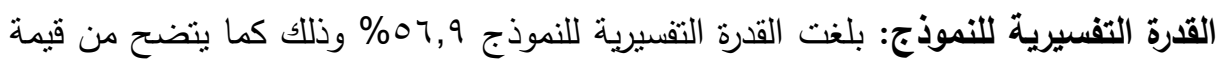
R square

المستقل.

والشكل التالي يوضح تلك العلاقة:

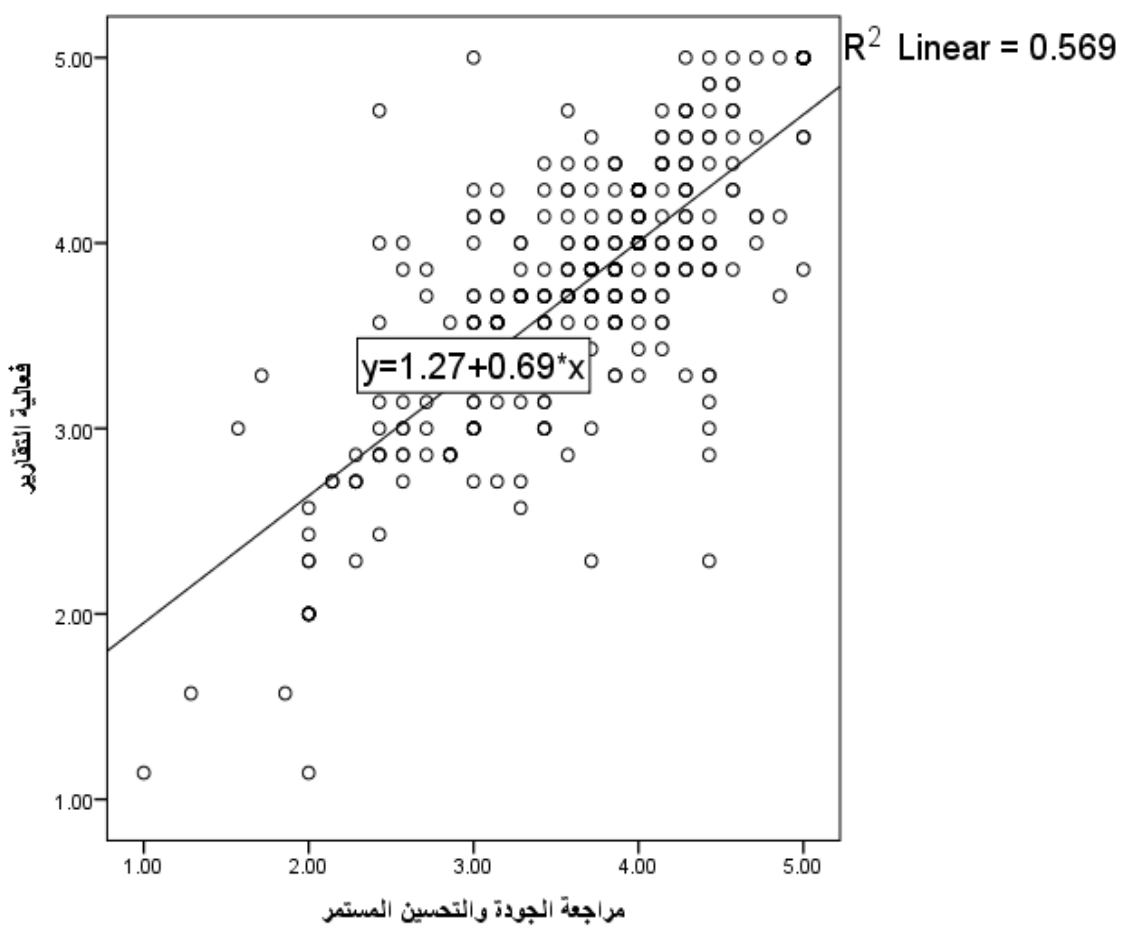

شكل(؛) : العلاقة بين تطبيق مراجعة الجودة التحسين المستمر وفعالية التقارير مما سبق نخلص إلى رفض الفرض الفرعي الثالث.

دـ اختبار الفرض الفرعي الرابع: لايوجد علاقة ارتباط بين تطبيق مراجعة الجودة

التحسين المستمر وكفاءة وفعالية المراجع الداخلي.

498

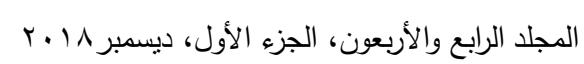


Simple Regression ولاختبار هذا الفرض تم إجراء تحليل الانحدار الخطي البسيط بين تطبيق مراجعة الجودة والتحسين المستمر، وكفاءة وفعالية المراجع الداخلي، وجاءت

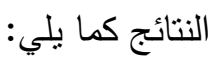
جدول(V): نتائج الانحدار البسيط بين تطبيق مراجعة الجودة والتحسين المستمر، ونتائج

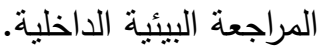

\begin{tabular}{|c|c|c|c|c|c|c|c|}
\hline \multicolumn{7}{|c|}{ 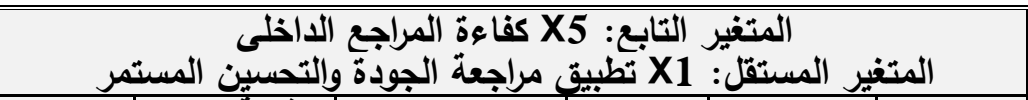 } & \multirow[b]{2}{*}{$\begin{array}{c}\mathbf{F} \\
\end{array}$} \\
\hline 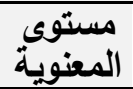 & المَحسوية & حامل & قي & $\mathbf{R}$ & $\begin{array}{c}\mathbf{R} \\
\text { square }\end{array}$ & المعنوية & \\
\hline$\cdot$ & $0,1 \varepsilon$ & $\cdot, \mathrm{V} \cdot \Lambda$ & $=\alpha$ & \multirow{2}{*}{$\cdot, \vee \leqslant}$. & \multirow{2}{*}{$\cdot, 0 \leqslant V$} & \multirow{2}{*}{$\cdot, \cdots$} & \multirow{2}{*}{$\leq 71,1$} \\
\hline$\cdots, \ldots$ & $r 1,0$ & $\cdot, \wedge \cdot 1$ & $=\beta$ & & & & \\
\hline
\end{tabular}

يتضح من الجدول (V) ما يلي: أظهرت نتائج الانحدار وجود علاقة طردية ذات دلالة معنوية بين X1 "تطبيق مراجعة الجودة والتحسين المستمر"، وبين X5 " كفاءة المراجع الداخلي"،

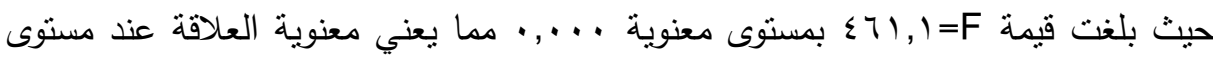
معنوية ا.,.•، أي أن تطبيق مراجعة الجودة والتحسين المستمر يؤثز طردياً على كفاءة

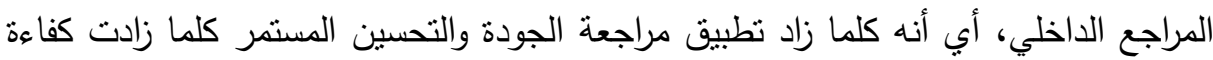
المراجع الداخلي. بعد تقدير معالم نموذج الانحدار يمكن صياغة معادلة الانحدار بالثكل التالي: X5 $=0.708+0.801 * X 1+\varepsilon$

اختبار معنوية المتغير المستقل: يتضح معنوية المستقل وذلك من اختبار T test حيث

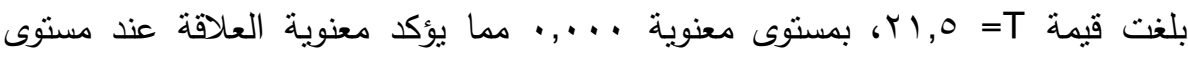

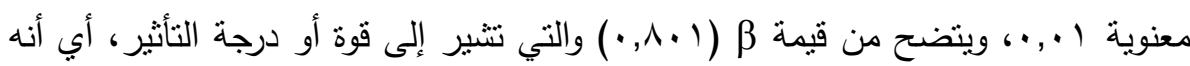


كلما زاد تطبيق مراجعة الجودة والتحسين المستمر بدرجة واحدة يتبعها زيادة في كفاءة

$$
\text { المراجع الداخلي بمقدار (1 (1), ·) درجة. }
$$

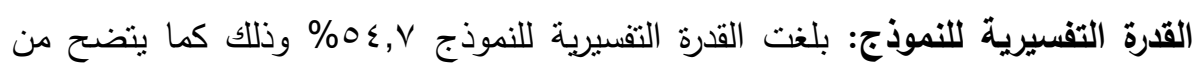

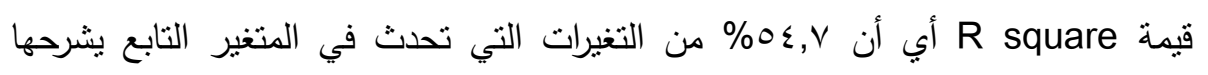

المتغير المستقل.

والثكل التالي يوضح تلك العلاقة:

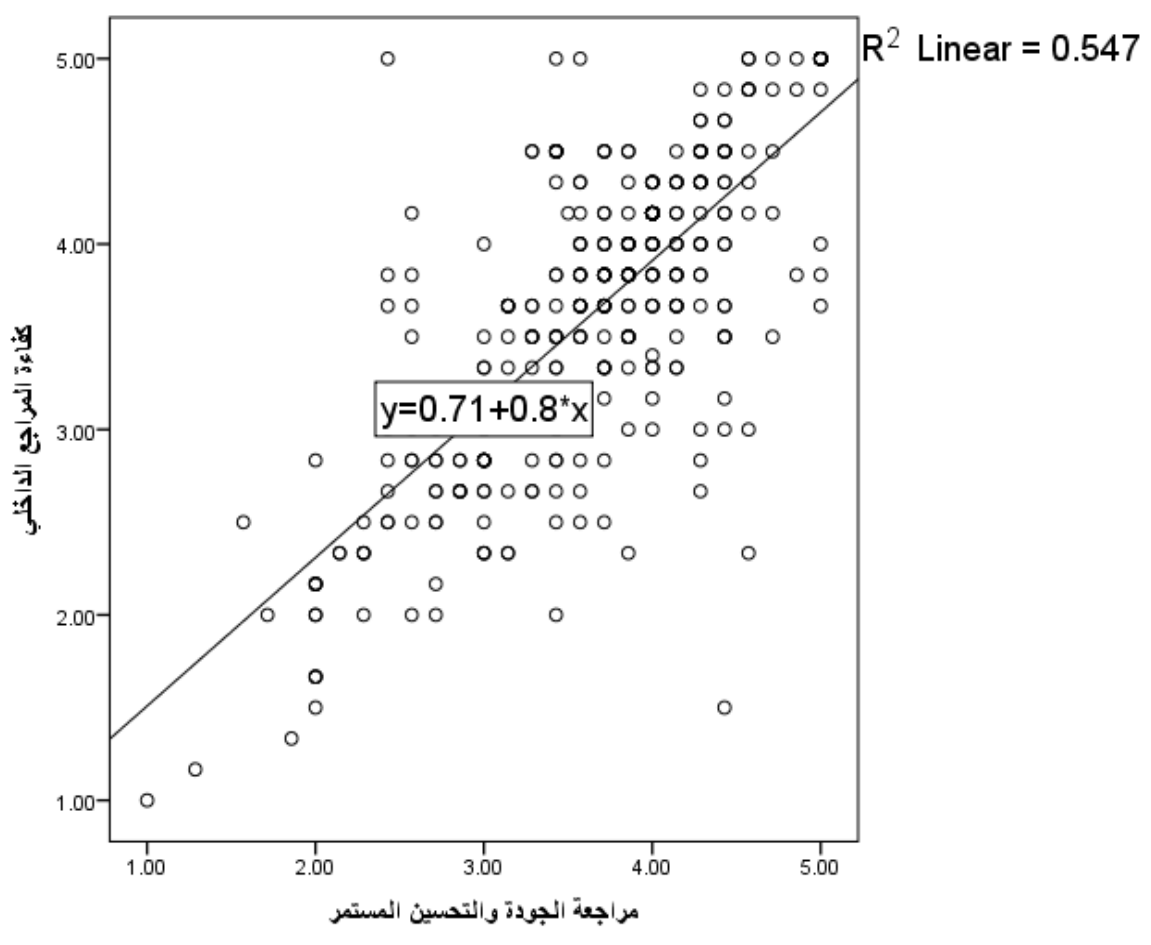

شكل(ه): يوضح العلاقة بين تطبيق مراجعة الجودة والتحسين المستمر ، وكفاءة المراجع الاخلي

مما سبق نظلص إلى رفض الفرض الفرعي الرابع.

من النتائج السابقة نخلص إلى رفض الفرض الرئيس نظراً لرفض فروضه الفرعية 


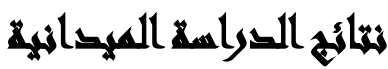

بعد تحليل بيانات الدراسة الميدانية توصل الباحثون للنتائج التالية: نتائج خاصة بعينة الاراسة: تتوعت العينة من حيث المؤهل العلمي حيث وجد أن نسبة

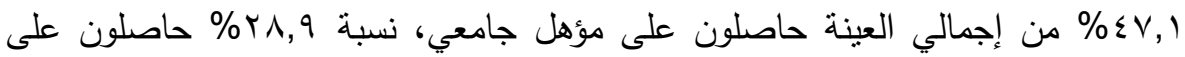
مؤهل أعلى من الجامعي، بينما الحاصلون على مؤهل متوسط وغير المتوسط فقد بلغت هون

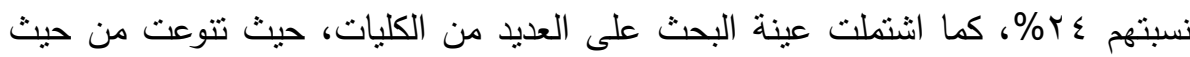

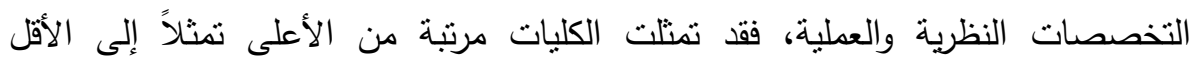
(التجارة، الطب، الحقوق، الآداب، الهندسة، البنات، الألسن، طب الأسنان، معهد البحوث)

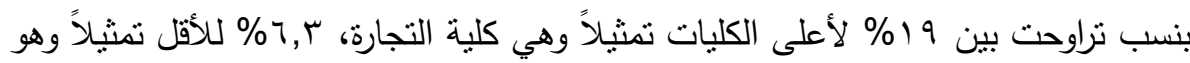

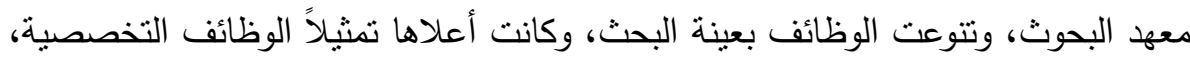

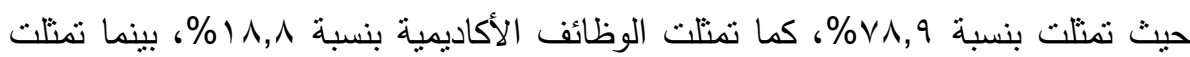

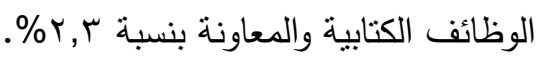

\section{Reliability نتائج خاصة باختبارات صلاحية البيانات} • تراوحت قيمة ألفا (معامل الثبات) Cronbatch's Alfa بين \& VY, •، Y • 9, • على محاور قائمة الاستقصاء، والذي انعكس بدوره على مستوى الصدق، حيث نراوح بين

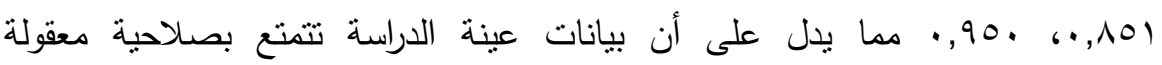
Reliability ثنات الاستجابات وإمكانية الاعتماد على النتائج وتعميم هذه النتائج على مجتمع الدراسة.

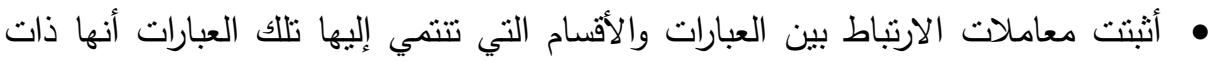
دلالة معنوية عند مستوى معنوية ا.,,. مما يدل على التتاسق الداخلي Internal Consistency وضعت لقياسه، كما دل التحليل العاملي التوكيدي على صدق المقياس الذي صممه الباحث لقياس أقسام الدراسة.

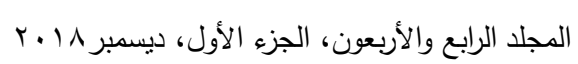


في ضوء نتائج الدراسة الميدانية، والفروض التي تم اختبارها، يوصي

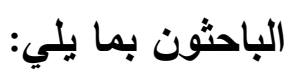

• أثنتت الدراسة إدارك عينة البحث لأهمية دور مراجعة الجودة والتحسين المستمر

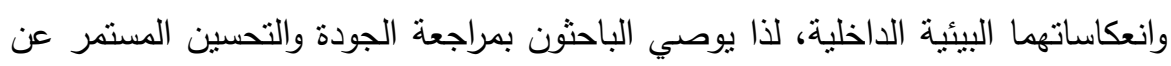
طريق ضرورة قيام المنشأة بما يلي: • تقديم الخطط اللازمة لتحسين الجودة بعد تحديد المشكلات وجمع البيانات الضرورية وتحليلها.

• ت تفيذ الخطط وتطبيق التغيير في حدود المطلوب لحل المشكلة. • قياس النتائج وتقييمها، وفي حالة نجاح النتائج يتم تطبيق خطط التحسين، وفي حالة وجود

$$
\text { قصور يتم دراسة نواحي القصور ومعالجتها. }
$$

• قبام قسم المراجعة البيئية الداخلية في المنشأة بممارسة الرقابة على الفعليات والانشطة

• أثتتت النتائج أن تحقيق مستوى الكفاءة التشغيلية للمنشآت يعاني من قصور، لذا يوصي

$$
\text { الباحثون بدراسة نواحي القصور ومعالجتها. }
$$

• • ضرورة الاهتمام بتطوير ورفع كفاءة المراجع الداخلي عن طريق القيام بما يلي:

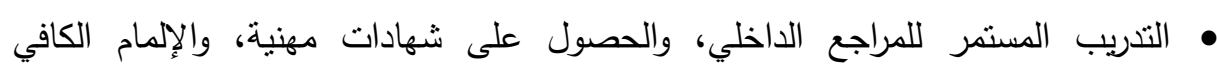
بالمعايير الدولية للمراجعة الداخلية. • توفير الاستقلالية للمراجع الداخلي في كتابة التقارير وضرورة إظهار كافة الحقائق التي يتم اكتشافها دون تدخل أي طرف.

\section{المرالئ2}

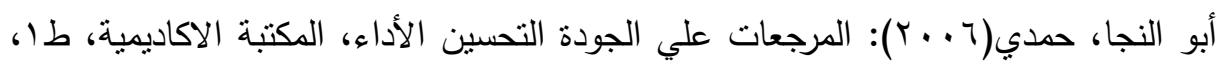

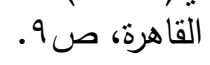

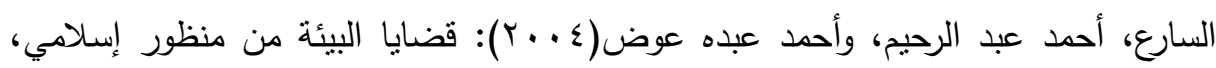

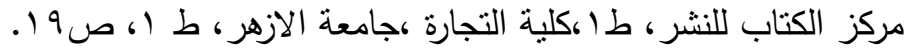




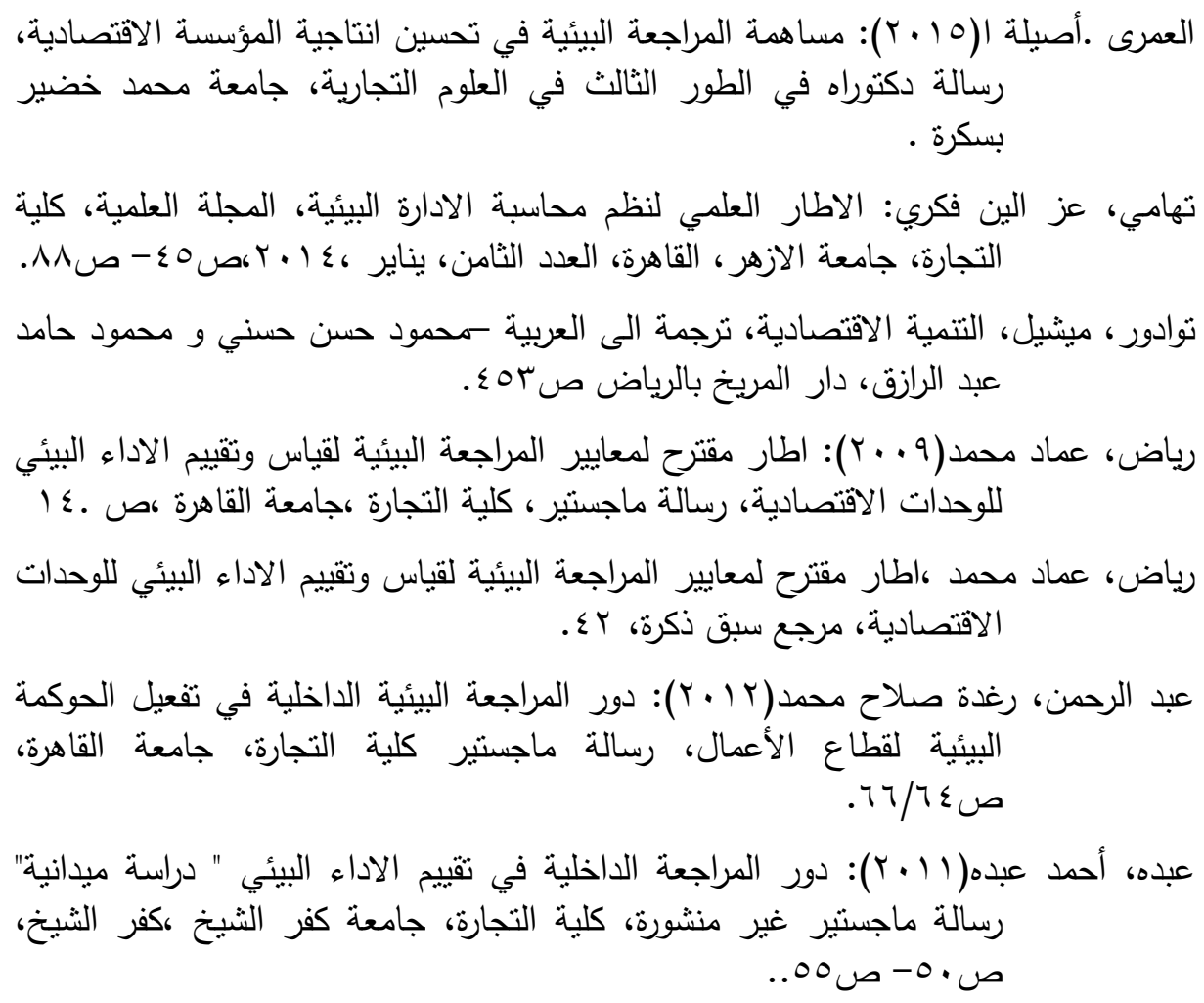

Douglas, B.-Christopher C. ,(1999): "Corporate Environmental Reports: The Need for standards and An Environmental Assurance Service", Accounting Horizons, June,pp.129-145.

Mihaela Ungureanu; (2013): "Role of Environmental Auditin the Modem Enterprise" European Social Fund in Romania, under the responsibility of the Managing Authority For the Sectorial O PERATIONAL program For Human Resources Development pp.1-8.

Vivi niemenmaa, 'Environmentl Auditing: Current and Future ",Intmational, Joumal of Covemment Auditing, Hill Book, Candan, July,2012, p.22 Challenges

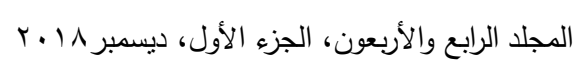


طارق صبحي عبد الحميد وآخرون

\title{
THE IMPACT OF APPLYING QUALITY AUDITING AND CONTINUOUS ENHANCING ON INCREASING THE EFFECTIVENESS OF THE INTERNET ENVIRONMENTAL AUDITING
}

\author{
Abdel Hameed, T. S. ${ }^{(1)}$; Khatab, G. S. ${ }^{(1)}$ and El-Barry, Amany ${ }^{(1)}$ \\ 1) Faculty of Commerce, Ain Shams University
}

\begin{abstract}
This study drives at identifying the impact of applying quality and continual improving for the purpose of increasing efficiency of internal environmental auditing for reaching targeted efficacy. The study counts on a group of hypotheses for testing the potentiality of applying quality auditing and continual improving and its impact on the internal environmental auditing as a vital source for achieving the competitive advantage in terms of globalization of markets and its being affected by essential everlasting changes in economic activity setting. The study also drives at identifying the new originated tasks of internal environmental auditing in light of contemporary environment of quality and continual improvement, checking as well the impact of applying quality auditing and continual improvement regarding its progress and for promoting its efficiency and effectiveness.

For achieving the previous objectives, the researchers count on the theoretical approach using the inductive-deductive and descriptiveanalytical method through books, references, Arabic and foreign studies. Achieving this, the researchers use through applying the field study an investigation form for the top management, auditors, and the auditing committee in application on Ain Shams University.

The researchers have distributed about (450) investigation forms on research sample, collecting (388) as retrieved forms with response ratio about $86.2 \%$. (384) lists are used in the statistical analysis, with response ratio about $85.3 \%$. The regression results indicate a significant

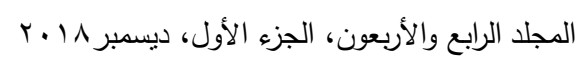


direct relationship between X1 "application of quality auditing and continual improvement" and X3 "results of internal environmental auditing" since $\mathrm{F}=652.2$ value at $(0.000)$ significance level, meaning that the relation is significant at $(0.01)$ level; meaning also that the application of quality auditing and continual improvement affects directly the results of internal environmental auditing, meaning that the more application of quality auditing and continual improvement, the more are the positive results of internal environmental auditing. 